\title{
RETRACTION
}

\section{ANCIENT SOLUTIONS OF CODIMENSION TWO SURFACES WITH CURVATURE PINCHING - RETRACTION ZHENGCHAO JI(D)}

doi: 10.1017/S0004972720000179, Published by The Australian Mathematical Society, 6 March 2020

At the request of the Editor, the Author has agreed to retract the paper [2] and apologises for quoting extensively from the papers [1,3] without proper acknowledgement. The Author also notes that some details in the proofs in Section 4 of [2] require correction.

\section{References}

[1] C. Baker and H. T. Nguyen, 'Codimension two surfaces pinched by normal curvature evolving by mean curvature flow', Ann. Inst. H. Poincaré Anal. Non Linéaire 34 (2017), 1599-1610.

[2] Z. Ji, 'Ancient solutions of codimension two surfaces with curvature pinching', Bull. Aust. Math. Soc. 102(1) (2020), 162-171.

[3] S. Risa and C. Sinestrari, 'Ancient solutions of geometric flows with curvature pinching', J. Geom. Anal. 29 (2017), 1206-1232.

ZHENGCHAO JI, Center of Mathematical Sciences, Zhejiang University, Hangzhou 310027, PR China

e-mail: jizhengchao@zju.edu.cn

(C) 2021 Australian Mathematical Publishing Association Inc. 